\title{
CONCORDANCE AND DISCORDANCE OF ANENCEPHALY IN 109 TWIN PAIRS IN JAPAN
}

\author{
Yoko IMAIZUMI \\ Institute of Population Problems, Ministry of Health and Welfare \\ of Japan, Kasumigaseki, Tokyo, Japan
}

\begin{abstract}
Summary One hundred and nine pairs of twin with anencephaly were ascertained during the period from 1969 to 1976 in Japan. The rate of concordance in anencephalic twins was $8.3 \%$ and seems to be higher than those of previous reports.
\end{abstract}

\section{INTRODUCTION}

The indications of genetic factors in the etiology of anencephaly come from an influence of parental consanguinity, a specific familial aggregation and twin studies (Carter, 1974). The recurrence risk after the birth of the first anencephalic child in a sibship was about $4 \%$, but after two affected sibs the risk rose to $13 \%$ (Masterson, 1962). On the other hand, the concordance rate for anencephalic twins was very low (Lemire et al., 1977), although published data on anencephalic twins were not enough (Rogers and Weatherall, 1976).

In Japan the twin concordance rate for anencephaly was reported to be zero in a previous study (Imaizumi, 1974). The present communication deals with further analyses of observation on such twins including additional data thereafter obtained.

\section{MATERIAL}

Data on anencephalic twins were obtained from the fetal death and postnatal death certificate records reported during the period from 1969 to 1976 . Details about the certificate records have been reported elsewhere (Imaizumi, 1974).

\section{RESULTS AND DISCUSSION}

Table 1 shows twin concordance and sex of twin sets with anencephaly. Data on anencephalic twins for the 38 among 109 pairs were published by Imaizumi (1974). Nine among 109 pairs $(8.3 \%)$ of twin were concordant. The sex of twins was ascertained for the 62 among 109 twin pairs. The number of like-sexed twin pairs were 56 and the number of unlike-sexed twin pairs were six. Sex of one 
Table 1. Twin concordance of anencephalic cases.

\begin{tabular}{|c|c|c|c|c|c|c|c|c|c|c|c|c|c|}
\hline \multirow{3}{*}{ Years } & \multirow{2}{*}{\multicolumn{3}{|c|}{$\frac{\text { Concordant }}{\text { Sex of twin sets }}$}} & \multicolumn{9}{|c|}{ Discordant } & \multirow{3}{*}{ Total } \\
\hline & & & & \multicolumn{9}{|c|}{ Sex of twin sets } & \\
\hline & $\mathrm{MM}$ & FF & MF & $\overline{\mathrm{MM}^{*}}$ & $\mathrm{FF}^{* *}$ & $\mathrm{MF}^{*}$ & $\mathrm{FM}^{*}$ & $M ?^{*}$ & $\mathrm{~F} ?^{*}$ & $? \mathrm{M}^{*}$ & ?F* & $? ?^{*}$ & \\
\hline $1969-1971$ & 0 & 0 & 0 & 7 & 10 & 2 & 0 & 8 & 7 & 1 & 0 & 3 & 38 \\
\hline 1972-1974 & 3 & 3 & 1 & 11 & $41^{\dagger}$ & 0 & 1 & 10 & 9 & 0 & 0 & 0 & 42 \\
\hline $1975-1976$ & 0 & 1 & 1 & 11 & 6 & 1 & 0 & 2 & 6 & 0 & 1 & 0 & 29 \\
\hline Total & 3 & 4 & 2 & 29 & 20 & 3 & 1 & 20 & 22 & 1 & 1 & 3 & 109 \\
\hline
\end{tabular}

$\mathrm{M}^{*}$, unaffected male; $F^{*}$, unaffected female; ?*, unaffected unknown sex; $\dagger$, one twin pair has anencephaly and congenital hydrocephaly.

member or both of a twin pair was unknown in the remaining 47 pairs. The proportion of unlike-sexed twins in the general population was $16.11 \%$ in Japan (Ministry of Health and Welfare of Japan, 1974), and the value in this study was $9.68 \%$ (6/62). The difference between both values is statistically significant at the $0.1 \%$ level. Namely, the deficiency of unlike-sexed twins was observed in anencephalic twins.

James (1976) mentioned that concordance rates are higher in the like-sexed than in the unlike-sexed pairs. On the other hand, in the present study, concordance rates were $13 \%(7 / 56)$ in like-sexed and $33 \%(2 / 6)$ in unlike-sexed pairs. However, in the latter case, the sex distribution of 47 twin pairs among 109 pairs were unknown.

Rogers and Weatherall (1976) have assembled from the literature a series of 681 twin pairs with anencephaly or spina bifida. Rogers (1976) used these data and estimated that the concordance rates were $17.8 \%(26 / 146)$ and $1.6 \%(8 / 535)$ for monozygous and dizygous twins, respectively. However, the value for dizygous twins was very low compared with the recurrence risk in sibs born after an affected child. Table 2 shows twin concordance and sex of anencephaly which were obtained from the literature. Nineteen among 422 pairs of twins are concordant, and the concordance rate is $4.5 \%$. The sex distribution of six twin pairs among 422 pairs in Table 2 were unknown. It is generally accepted that approximately $70 \%$ of likesexed twins are dizygous (Rogers, 1976). When the total of 299 like-sexed pairs 284 discordant and 15 concordant) is divided into $70 \%$ dizygous and $30 \%$ monozygous twins, 209 dizygous and 90 monozygous twins are obtained in the like-sexed pairs. From these numbers, the 15 concordant like-sexed pairs were estimated to be composed of 7 dizygous twins $(4 \times 209 / 117)$ and 8 monozygous twins. Therefore, the concordance rate is $8.9 \%(8 / 90)$ for monozygous and $3.4 \%(11 / 326)$ for dizygous twins.

Overall concordance rate in the present study was $8.3 \%(9 / 109)$ and seems to be higher than those in other investigations (see Rogers and Weatherall, 1976; James, 1976; Janerich and Piper, 1978). However, the results are not conclusive and further investigation is needed. 


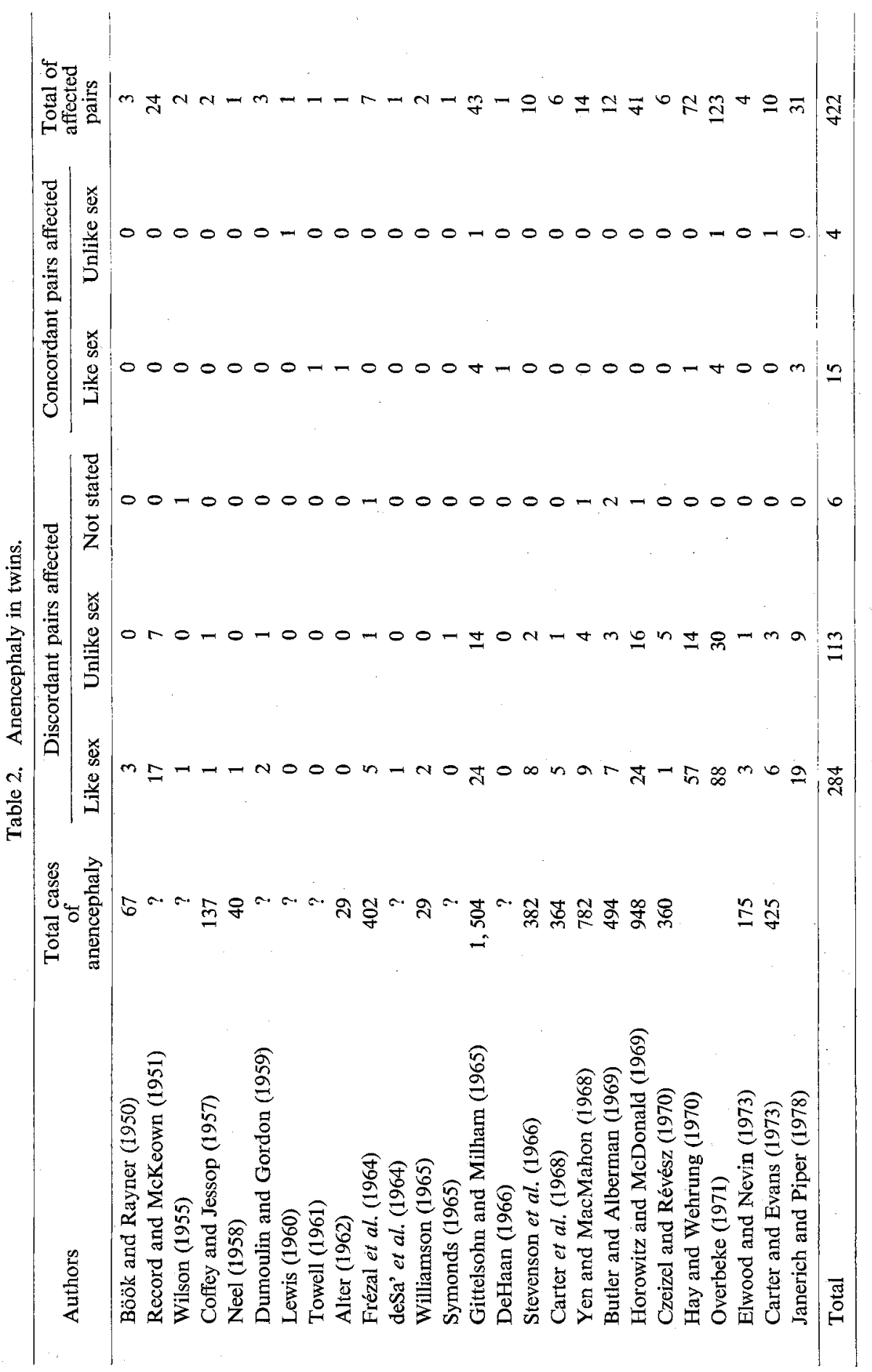


Acknowledgements This investigation was supported in part by the Grant Aided by the Ministry of Health and Welfare of Japan for the Handicapped Children, 1977.

I am indebted to Professor E. Inouye of the University of Tokyo for his helpful comments.

\section{REFERENCES}

Alter, M. 1962. Anencephalus, hydrocephalus and spina bifida. Arch. Neurol. 7: 411-422.

Böök, J.A. and Rayner, S. 1950. A clinical and genetic study of anencephaly. Am. J. Hum. Genet. 2: 61-84.

Butler, N.R. and Alberman, E.D. (eds.) 1969. Perinatal Problems: The Second Report of the 1958 British Perinatal Mortality Survey. Livingstone, Edinburgh and London.

Carter, C.O. 1974. Clues to the aetiology of neural tube malformations, Dev. Med. Child Neurol. 16 (Suppl. 32): 3-15.

Carter, C.O., David, P.A., and Laurence, K.M. 1968. A family study of major central nervous system malformations in South Wales. J. Med. Genet. 5: 81-106.

Carter, C.O. and Evans, K. 1973. Spina bifida and anencephalus in Greater London. J. Med. Genet. 10: 209-234.

Coffey, V.P. and Jessop, W.J.E. 1957. A study of 137 cases of anencephaly. Br. J. Prev. Soc. Med. 11: $174-180$.

Czeizel, A. and Révész, C. 1970. Major malformations of the central nervous system in Hungary. Br. J. Prev. Soc. Med. 24: 205-222.

deSa, D.J., Strong, S.J., and Corney, G. 1964. Anencephaly in one of monozygous twins. Biol. Neonate. 7: 328-334.

DeHaan, Q.C. 1966. Monozygotic anencephalic twins. Obstet. Gynecol. 28: 559-560.

Dumoulin, J.G. and Gordon, M.E. 1959. Anencephaly in twins. J. Obstet. Gynaecol. Br. Emp. 66: 964-968.

Elwood, J.H. and Nevin, N.C. 1973. Factors associated with anencephalus and spina bifida in Belfast. Br. J. Prev. Soc. Med. 27: 73-83.

Frézal, J., Kelly, J., Guillemot, M.L., and Lamy, M. 1964. Anencephaly in France. Am. J. Hum. Genet. 16: 336-350.

Gittelsohn, A.M. and Milham, S., Jr. 1965. Vital record incidence of congenital malformations in New York State. In: Genetics and the Epidemiology of Chronic Diseases, Neel, J.V., Shaw, M.W., and Schull, W.J., eds. (Public Health Service Publication No. 1163). U.S. Department of Health, Education, and Welfare, Washington, D.C., pp. 305-319.

Hay, S. and Wehrung, D.A. 1970. Congenital malformations in twins. Am. J. Hum. Genet. 22: 662-678.

Horowitz, I. and McDonald, A.D. 1969. Anencephaly and spina bifida in the Province of Quebec. Can. Med. Assoc. J. 100: 748-755.

Imaizumi, Y. 1974. Statistical analysis on anencephaly, spina bifida and congenital hydrocephaly in Japan. Jap. J. Human Genet. 9: 115-135.

James, W.H. 1976. Twinning and anencephaly. Ann. Hum. Biol. 3: 401-409.

Janerich, D.T. and Piper, J. 1978. Shifting genetic patterns in anencephaly and spina bifida. J. Med. Genet. 15: 101-105.

Lemire, R.J., Beckwith, J.B., and Warkany, J. 1977. Anencephaly. Raven Press, New York.

Lewis, L. 1960. A case of twin anencephalic pregnancy. Br. Med. J. 19: 1500-1501.

Masterson, J.G. 1962. Empiric risk, genetic counseling and preventive measures in anencephaly. Acta Genet. (Basel) 12: 219-229.

Ministry of Health and Welfare of Japan. 1977. Survey on Socio-economic Aspects of Vital Events-Plural Births, 1975. Health and Welfare Statistics Division, Minister's Secretariat, Tokyo. 
Neel, J.V. 1958. A study of major congenital defects in Japanese infants. Am. J. Hum. Genet. 10: 398-445.

Overbeke, J. 1971. Anencephalie in Nederland 1951-1968. Cited from James (1976).

Record, R.G. and McKeown, T. 1951. Congenital malformations of the central nervous system: Data on 69 pairs of twins. Ann. Eugen. 15: 285-292.

Rogers, S.C. 1976. Anencephalus, spina bifida, twins, and teratoma. Br. J. Prev. Soc. Med. 30: 26-28.

Rogers, S.C. and Weatherall, J.A.C. 1976. Anencephalus, spina bifida and congenital hydrocephalus. England and Wales 1964-1972. HMSO, London.

Stevenson, A.C., Johnston, H.A., Stewart, M.I.P., and Golding, D.R. eds. 1966. Malformations of structures developed from the neural tube (B1-B7). Chapter 4 in Congenital Malformations, Bull. World Health Org. 34, Suppl.: pp. 25-34.

Symonds, E.M. 1965. Anencephaly and hydrocephaly in a twin pregnancy: Report of case. Obstet. Gynecol. 26: 414-416.

Towell, M.E. 1961. Dizygotic anencephalic twins (microcephaly craniorhachischisis): Case report. J. Obstet. Gynaecol. Br. Commonw. 68: 303-306.

Williamson, E.M. 1965. Incidence and family aggregation of major congenital malformations of central nervous system. $J . M e d$. Genet. 2: 161-172.

Wilson, J.K. 1955. Mono-amniotic multiple pregnancy. J. Obstet. Gynaecol. Br. Emp. 62: 605-609. Yen, S. and MacMahon, B. 1968. Genetics of anencephaly and spina bifida. Lancet 2: 623-626. 